\title{
ENSINAR E APRENDER PORTUGUÊS: A DIGITAL RESOURCE FOR LEARNING TO READ AND WRITE
}

\author{
I. Ribeiro', F. L. Viana'2, R. Ramos ${ }^{3}$, I. Cadime', S. Santos ${ }^{4}$ \\ ${ }^{1}$ Psychology Research Centre (CIPsi), University of Minho (PORTUGAL) \\ ${ }^{2}$ Research Centre on Child Studies (CIEC), University of Minho (PORTUGAL) \\ ${ }^{3}$ Institute of Education (IE), University of Minho (PORTUGAL) \\ ${ }^{4}$ Centre for Research in Higher Education Policies (PORTUGAL)
}

\begin{abstract}
In Education, the use of technological resources to support students' teaching and learning is becoming more and more urgent. Teaching and Learning Portuguese [Ensinar e Aprender Português - EAP] is a structured and innovative educational resource, supported by the use of Information and Communication Technologies and based on scientific evidence. It is aimed at students (and teachers) of the four years of primary school. It aims to: i) support the teaching/learning of reading and writing in primary school; ii) signalize, in a timely manner, students at-risk of presenting difficulties in learning to read and write; and iii) support the recovery of learning. This paper will present this digital resource developed for the Portuguese context, based on the Portuguese curriculum and the legislation on inclusive education. It is also anchored in the multilevel approach whose focus on digital transition, on screening tests and monitoring of learning has introduced new challenges in the education system. As it is a digital resource whose activities are self-executable and for which explanatory and corrective feedbacks are provided, it contributes to bridge a gap in terms of digital transition which was particularly visible in a pandemic context such as the one we are going through.
\end{abstract}

Keywords: teaching mother tongue, primary school, digital resources, digital transition.

\section{INTRODUCTION}

The need to integrate information and communication technologies (ICT) in education became particularly evident during the COVID-19 pandemic [1]. A little all over the world, face-to-face teaching has been replaced by distance learning for extended periods [2], [3], and, even in periods when the modality was face-to-face, many students continued with distance learning due to illness, quarantine, or prophylactic isolation. However, the relevance of ICT in education is not only justified by a historical and, certainly, transitory moment, associated with the COVID-19 pandemic. Its importance is broader. Firstly, students who currently attend basic, secondary and higher education will be increasingly "more virtual" and digital literacy will constitute a transversal and essential competence. Secondly, the need to consider the heterogeneity of students and their family and geographic contexts, and the need to ensure pedagogical differentiation, identify students at-risk in a timely manner, monitor their learning and ensure quality universal education within the framework of a multilevel approach are challenges that are imposed on several educational systems [4], [5], including the Portuguese system. Integrating digital resources in the teaching of reading and writing competences not only contributes to the promotion of digital literacy, but also can help dealing with the listed challenges.

The digital resource "Teaching and Learning Portuguese - EAP" (https://lusoinfo.com/EAPT/EAPT.pdf) is a digital resource whose main objectives are: (a) to provide teachers with a resource to improve their practice in order to contribute to the enhancement of students' learning, by providing support for the organization of responses adjusted to the pace of the students, by helping the timely identification of students at-risk and by facilitating the monitoring of their evolution in reading and writing; (b) to support the acquisition of reading and writing whether teaching is made in the modalities of face-to-face, mixed or distance teaching; (c) to promote digital literacy and facilitate digital transformation; (d) to develop self-regulation and the development of learning strategies; (e) to respond to the challenges of equity and inclusion; (f) to promote the motivation for reading.

\section{METHODOLOGY}

The resource EAP was built taking into account the program for the teaching of Portuguese in primary school, the list of essential competences to be learned, the content of the Decree-Law 54 of 8 July 2018 
and its updates, the research related to the teaching of reading and writing [6]-[8], motivation for reading and self-regulation [9], [10], and the principles of the multilevel approach [11].

\subsection{Materials}

The EAP teaching content/activities are organized by grade. There are the specific activities for each grade. Each student can also have access to the activities of previous academic years. The activities are labelled "level 1", "level 2", "level 3" and "level 4", corresponding each level to each of the four grade levels of primary school in Portugal. The integration of activities from previous years allows the teacher to select activities suitable for students, who, although enrolled in a specific grade, may need to consolidate content from previous years.

The downloadable teaching materials, videos, multimedia activities, working and/or consolidation documents are organized in the following tabs: "Learning to read and write"; "Comprehension of oral text"; "Comprehension of written text"; "Reading fluency"; "Orthography"; "Grammar"; "Literary education"; and "Writing projects". Screening and monitoring tests for each grade are available in the "Evaluation" tab. The results of the students obtained in these tests are made available to teachers in the "Results" tab. The information of each class is confidential and only the respective teacher in charge of the class has the necessary permissions to access that information. The resource also includes an introductory video and virtual tutors. Each of these elements is briefly described in the following subsections.

\subsubsection{Brief history of learning to read and write}

Presentation in video format of the origin of writing. It is used to explain the importance of learning to read and write.

\subsubsection{Team "Learning to read and write Portuguese"}

Composed of seven virtual tutors (cf. Fig. 1). They monitor the performance of the students, provide explanations, remember rules (e.g. in spelling), teach learning strategies, anticipate difficulties and drive the student's attention to them, activate previous knowledge, expand the background knowledge necessary to carry out some activities (e.g. in the comprehension tasks), ask questions in order to foster the students' curiosity, provide positive reinforcement and give feedback.

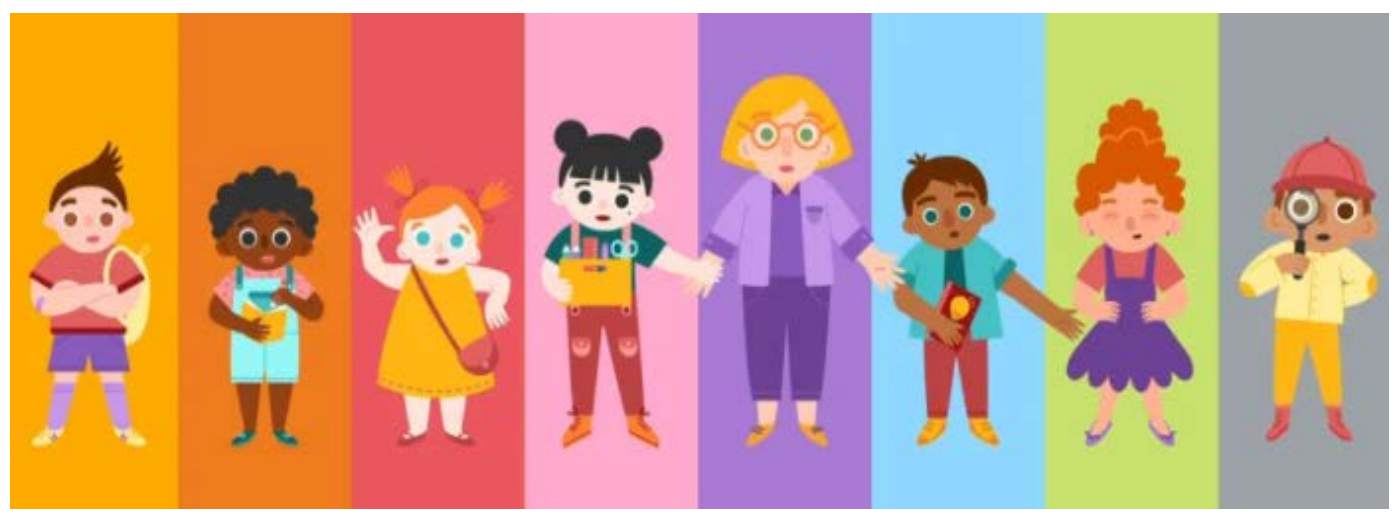

Figure 1 - Virtual tutors of the digital resource "Teaching and Learning Portuguese"

\subsubsection{Learning to read and write}

In the first grade, this domain consists of a set of multimedia activities that allow: (a) the identification of sounds in speech; (b) the association of speech sounds with their letter representation; (c) the teaching of phoneme-grapheme/grapheme-phoneme rules of correspondence; and (d) the consolidation of the reading and writing of words, sentences, and short texts. The activities are organized so that as students learn the phoneme-grapheme/grapheme-phoneme conversion rules, they start to automate reading and writing.

\subsubsection{Comprehension of oral text}

Includes a set of multimedia activities. The student can watch a video or hear a story, followed by a set of comprehension questions/tasks also presented in audio format. The question/task response format 
is varied, and the correction is automatically provided by the system. The student receives information on whether the answer given is correct/incorrect, accompanied by an explanation provided by one of the virtual tutors. In activities designed for the first grade, grammar activities were integrated in these sequences, to ensure that grammar is taught from occurrences extracted from these texts.

\subsubsection{Comprehension of written text}

Similar in structure to the comprehension of oral text. The main difference lies in the way of presenting the texts and the questions/tasks, given that, in this case, they must be read by the student.

\subsubsection{Reading fluency}

In this domain, a set of multimedia activities is proposed. In the first grade, the reading fluency training is carried out using phrases and short texts, following the sequence of teaching of the phonemegrapheme correspondences available in the domain "Learning to read and write". In the second grade, the training is carried out using only texts. Audio files are available to be used in the phase of model reading. Other strategies integrated in the activities include echo reading and repeated readings. It is also possible for the students to record their reading and perform self-assessment, by classifying their reading (accuracy, speed and prosody) in a qualitative way.

\subsubsection{Orthography}

A set of activities, called "magic pencils" are proposed, which aim to consolidate the learning of the alphabet, graphophonemic and phonographic correspondences, word writing and spelling rules. Specific rules are organized in a tool called "the library of tricks".

\subsubsection{Grammar}

The proposed multimedia activities are related to the texts heard or read.

\subsubsection{Writing projects}

Textual production is worked from the construction of projects. It involves activities related to planning, textualization and revision. The rules are explicitly taught, and students have access to a set of materials that improve the quality of the written text.

\subsubsection{Literary Education}

This domain includes two approaches. The first is related to the selection of the texts used the comprehension tasks. The second, specifically included in this tab, includes texts read by "storytellers" or by authors of books for children. Additionally, interviews with writers and illustrators are also available, as well as presentations of books that students are invited to read. Reading and listening texts for pleasure, without questions or tasks, is the main aim of the activities proposed here.

\subsubsection{Additional tools}

\section{+ Library of tricks}

It includes a set of short videos, which students can view whenever they need it. The explanation of rules is made by the virtual tutors.

\section{+ Reading passport}

This is a place where students can register the books they have read or heard to read, whatever the context in which this reading activity took place. It accompanies students throughout the four grades of primary school.

\section{+ Pocket dictionary}

To be built by the students with the support of the teacher. It allows the registration, in a virtual format, of new words and the multiple meanings they may have. It also accompanies students throughout the four grades of primary school. 


\section{$+\underline{\text { Mural }}$}

This is a virtual space in which students can share documents and work and receive comments from other users of the platform.

\section{+ Rewards system}

Depending on the accuracy of their answers, students receive a set of stars. When the percentage of correct answers is equal to or greater than $75 \%$, students receive a badge. Students who fail to obtain the badge in a first attempt can repeat the activity until they are able to correctly answer the number of questions that allow their assignment.

\section{+ Integrated videoconferencing system}

This is a system integrated in the platform where the EAP is hosted that allows videoconferences among the teacher, parents and students.

\subsection{Procedure}

The use of the resource requires, at least, that the teacher has a computer with an internet connection. In an ideal situation, each student should have their computer with internet access and headphones. The feature can be used on a computer, tablet or mobile phone, although the latter option is the least suitable due to the size of the screen. The access is made via an individual password. Each teacher has access to the activities performed by his/her class. The student's password is also provided to parents, who can access the EAP and monitor the child's learning process. Weekly, teachers can access a remote meeting, where they have support to deal with issues that arise in the use of the resource. A separate weekly meeting is also scheduled for parents, in which they can ask questions and ask for help they may need.

Three webinars about the resource were conducted. These webinars were afterwards uploaded and made available in social media (available at https://www.youtube.com/watch?v=fnlJEQdrFjM, https://www.youtube.com/watch?v=B3JC7P807gE, and https://www.youtube.com/watch?v=1D-ScYEaU2c).

\section{RESULTS}

The three live webinars were attended by more than 6000 participants. On May 10, 2021, they had received more than 28000 visualizations via the social media channels. Schools located in 40 municipalities across Portugal have signed up to use EAP and therefore it is currently being used with around 40000 students from the first and second grades.

\section{CONCLUSIONS}

EAP is an evidence-based resource to teaching learning and writing in Portuguese that can be used in a face-to-face, distance or mixed teaching situation. The available results suggest a high enrolment of teachers with the resource. Currently, only materials for first and second grades are available. The materials for the third and fourth grades are under development and will be made accessible in 20212022. Results of a pilot study to assess the efficacy of the resource in promoting students' reading and writing skills will soon be available. Future studies should also address the efficacy of this tool in teaching Portuguese as a second language.

\section{ACKNOWLEDGEMENTS}

This work was supported by the Portuguese Foundation for Science (FCT) and Technology and the Portuguese Ministry of Science, Technology and Higher Education through national funds within the framework of the Psychology Research Centre (UIDB/PSI/01662/2020) and the Research Centre on Child Studies (UIDB/CED/00317/2020). The authors thank the support of the partners Plano Nacional de Leitura, Programa Nacional de Promoção do Sucesso Escolar, Rádio Televisão Portuguesa, Biblioteca Lúcio Craveiro da Silva, Lusoinfo Multimédia and Edubox. 


\section{REFERENCES}

[1] H. M. Niemi and P. Kousa, "A case study of students' and teachers' perceptions in a Finnish high school during the COVID pandemic," Int. J. Technol. Educ. Sci., vol. 4, no. 4, pp. 352-369, 2020.

[2] D. Oesselmann, "Educação em tempos de Covid-19 - descrições, observações e questões, a partir de uma perspetiva alemã [The impact of the Covid 19 pandemic on school education in Germany]," Saber Educ., vol. 29, pp. 1-5, 2020.

[3] S. P. Gonçalves, "Education in the context of the pandemic: A look at the case of Portugal," Rom. pentru Educ. Multidimens., vol. 12, no. 1, pp. 78-85, 2020.

[4] J. R. Jenkins and R. E. O'Connor, "Early identification and intervention for young children with reading/learning disabilities," in Identification of Learning Disabilities: research to practice, R. Bradley, L. Danielson, and D. Hallahan, Eds. New Jersey: Lawrence Erlbaum Associates, 2002, pp. 99-149.

[5] D. F. Mellard, M. McKnight, and K. Woods, "Response to intervention screening and progressmonitoring practices in 41 local schools," Learn. Disabil. Res. Pract., vol. 24, no. 4, pp. 186-195, 2009.

[6] I. Ribeiro et al., "A utilização da plataforma 'Ainda estou a aprender' na avaliação e na intervenção nas dificuldades na aprendizagem da leitura: um estudo de caso [The platform 'I'm still learning' in the assessment and intervention in reading disabilities: A case study]," Calidoscópio, vol. 15, no. 1, pp. 30-44, 2016.

[7] F. L. Viana, I. Cadime, S. Santos, S. Brandão, and I. Ribeiro, "O ensino explícito da compreensão da leitura. Análise do impacto de um programa de intervenção [The explicit teaching of reading comprehension. Impact analysis of an intervention program]," Rev. Bras. Educ., vol. 22, no. 71, pp. 1-30, 2017.

[8] "LER - Leitura e Escrita: Recursos [Reading and Writing: Resources]." [Online]. Available: https://ler.pnl2027.gov.pt/.

[9] F. L. Viana et al., O ensino da compreensão leitora. Da teoria à prática pedagógica [The teaching of reading comprehension. From theory to pedagogical practice]. Coimbra: Almedina, 2010.

[10] G. J. Roberts, M. Solis, and B. Chance, "Embedding self-regulation into reading interventions to support reading and behavior outcomes," Teach. Except. Child., vol. 52, no. 2, pp. 78-86, 2019.

[11] D. Fuchs, L. S. Fuchs, and S. Vaughn, Response to intervention: a framework for reading educators. Newark: International Reading Association, 2008. 